\title{
3-Mercaptodihydrocarvone (True Carvone Hydrosulphide) and (1S, 4S, 5S)-4,7,7-Trimethyl-6-thia-1,5-bicyclo-[3,2,1]-octan-3-one
}

\author{
Michael Hargreaves, Ronald McDougall, and Laljibhai Rabari \\ North East London Polytechnic, Romford Road, Stratford, London E 15 LZ
}

Z. Naturforsch. $33 \mathrm{~b}$, 1535-1539 (1978); received January 18, 1978

Configuration, NMR, CD, (-)-3-Mercaptodihydrocarvone, (一)-(1 S, 4S, 5S)-4-7-7-Trimethyl-6-thia-1,5-bicyclo-[3,2,1]-octan-3-one

True carvone hydrosulphide has been prepared and its CD and ORD spectra examined. The spectra of another product from the reaction of carvone and hydrogen sulphide, which is probably a bi-cyclic thiane, have also been recorded.

Whereas the compound formerly known as carvone hydrosulphide is, in fact, dicarvone sulphide [1], the genuine hydrosulphide, (-)-3-mercaptodihydrocarvone, has now been prepared by the addition of hydrogen sulphide to (-)-carvone in the presence of a base following a procedure analogous to that of van Tamelen and Grant [2]. It had boiling point $150-151^{\circ} / 0.5 \mathrm{~mm}, n_{\mathrm{D}}^{19}, 1.5221[\alpha]_{\mathrm{D}}^{20}$ $-6.3^{\circ}(\mathrm{c}=4$ in chloroform, $\mathrm{l}=1)$. Altogether, three products were obtained and part of the ketone was recovered. One of the products was identified by melting point and infrared spectrum as that previously styled carvone hydrosulphide, here called dicarvone sulphide $\mathbf{1}$.<smiles>C=C(I)C1CC(=O)C(C)C(SC2CC(=O)CC(=O)C2C)C1</smiles>

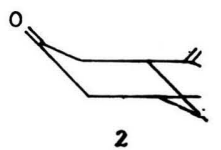

The remaining liquid, on distillation, gave two new isomeric compounds, one liquid and one solid, having the molecular formula $\mathrm{C}_{10} \mathrm{H}_{16} \mathrm{OS}$. The liquid product was assigned the structure 2 on the basis of its infrared and NMR spectra. It showed a positive Cotton effect, corresponding to the $n-\pi^{*}$ transition of the carbonyl group at $290 \mathrm{~nm}$ $(\theta=+5,250)$, a further positive Cotton effect at $235 \mathrm{~nm}(\theta=+1,520)$, and a negative Cotton effect below $220 \mathrm{~nm}$. The NMR spectra $(220 \mathrm{MHz})$ showed a signal (assigned to $\mathrm{C}-3 \mathrm{H})$ at $\delta 3.70 \mathrm{ppm}(J 7,3.8$, 3.5, 3.5 Hz) and to the $\mathrm{SH}$ proton at $\delta 1.22(J 7 \mathrm{~Hz})$. None of the coupling constants of $\mathrm{C}-3 \mathrm{H}$ is large

Requests for reprints should be sent to M. K. Hargreaves, Faculty of Sciences, Department of Chemistry, Head of Department, MK Hargreaves MA PhD DSe FRIC, Romford Road, London E15 4LZ, England. enough to allow for axial-axial coupling [3], thus an axial position is indicated for the mercapto group at C-3. Changing the solvent from deuteriochloroform to deuteriopyridine resulted in a downfield shift of the methyl doublet by $0.1 \mathrm{ppm}$. This indicates an equatorial position for the methyl group at C-2 [4]. Whilst the configuration of the carvone from which these compounds are derived has been established [5], the configuration of carvone hydrosulphide is only established by virtue of the argument above and, by the fact that the thiane 3 , which is likely to be derived from the hydrosulphide, must have the thiol and isopropenyl groups on the same side of the ring; given that the most likely preferred conformation is the chair form, formula 2 gives the most probable conformation. When 2 was treated with (-)-carvone 1 was obtained, which suggests that 2 is an intermediate stage in the formation of 1 . When 2 was treated with (+)-carvone a white solid with the same elemental composition as 1 was obtained. It was inactive and, presumably, the meso form of 1 . The ORD, CD and UV spectra of 2 are given in the Figures 1 and 2 ; the curves are different from those of the thiane but are rather similar in shape to those obtained from dicarvone sulphide.

The solid isomer from the preparation, $3, \mathrm{~m} . \mathrm{p}$. $89-90^{\circ}[\alpha]_{\mathrm{D}}^{20}-39.5^{\circ}(\mathrm{c}=2.5$ in chloroform, $\mathrm{l}=1)$ showed neither bands in the infrared spectrum at $2500-2600 \mathrm{~cm}^{-1}$, thus indicating the absence of an $\mathrm{SH}$ group [6], nor bands present at $3100-3010$ and 1650 and $900 \mathrm{~cm}^{-1}$, where cycloalkenes may be expected to absorb [7, 8]. There was a strong band at $1705 \mathrm{~cm}^{-1}$, indicative of the carbonyl group, and a doublet at 1365 and $1375 \mathrm{~cm}^{-1}$, indicating a gem dimethyl group [9]. The NMR spectrum (100 MHz) in deuteriochloroform showed a methyl doublet at $\delta 1.16 \mathrm{ppm}(\mathrm{C}-3 \mathrm{H} J 7 \mathrm{~Hz})$ and a methyl singlet at $\delta 1.42 \mathrm{ppm}(6 \mathrm{H})$ and is thus consistent with the 


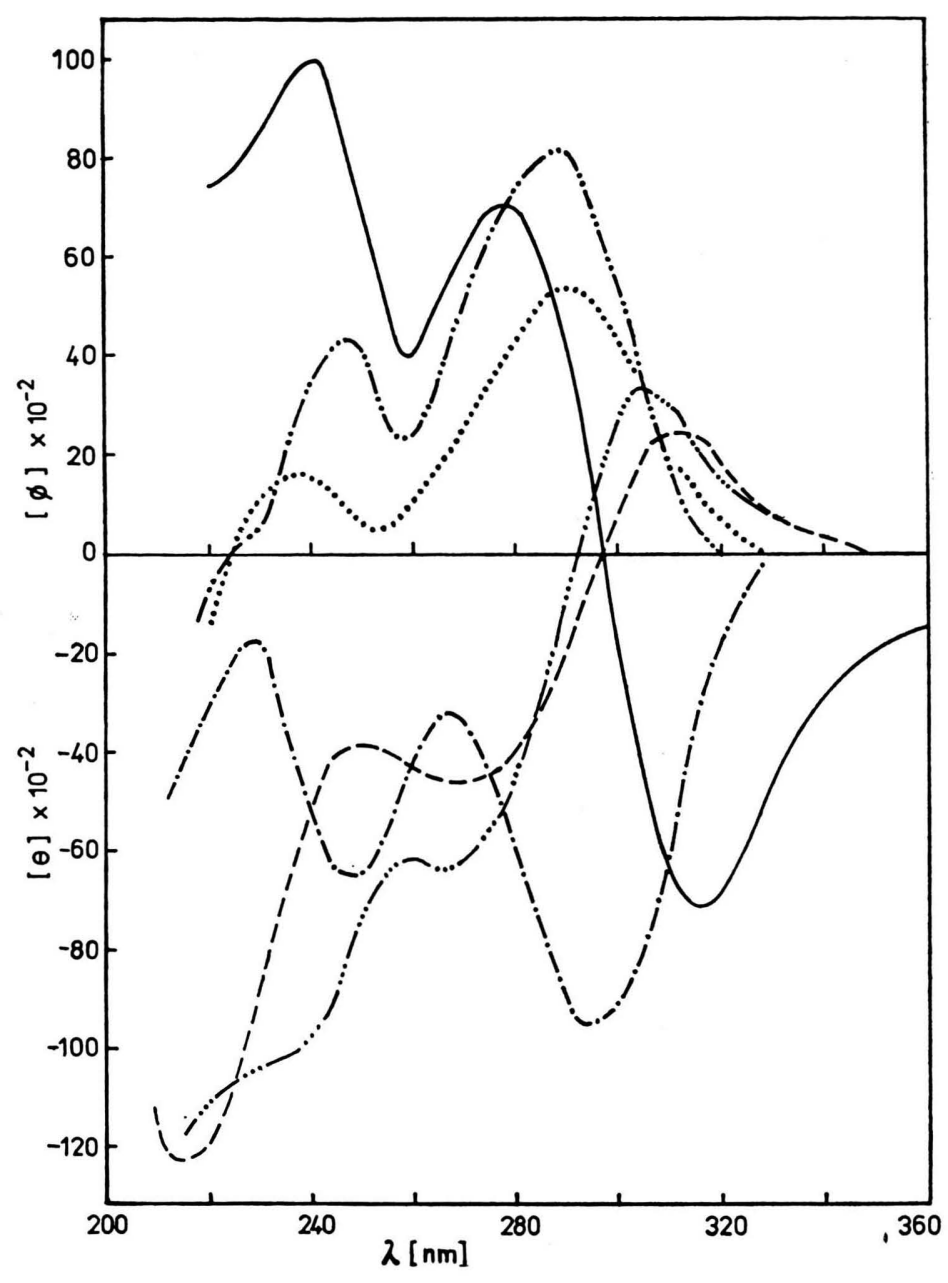

Fig. 1.

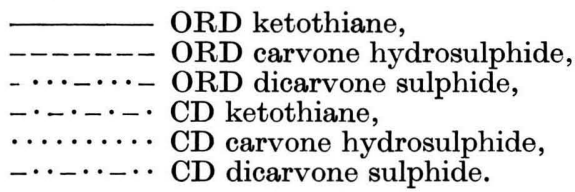

presence of a gem dimethyl group. There were maxima in the UV absorption at 206 and $239 \mathrm{~nm}$ ( $\varepsilon 2200$ and 920 ) with a shoulder indicative of a peak at $290-295 \mathrm{~nm}$, corresponding to the trough at $292 \mathrm{~nm}$ in the CD; the first two transitions correspond to a dialkyl sulphide [10], whilst the shoulder corresponds to the carbonyl group [11]. These various observations and the analysis suggest that
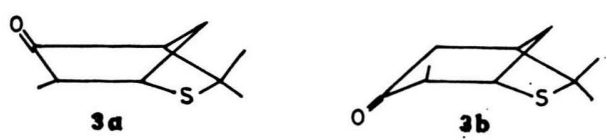

compound 3 is a bicyclic thiane. Since compound 3 is almost certainly derived from $\mathbf{2}$ by isomerisation (cyclisation) it is likely to have a structure such as $\mathbf{3 a}$ or $\mathbf{3 b}$.

It seems, from models, that the cyclisation would be easier in the boat rather than the chair form, thus giving $\mathbf{3 a}$ rather than $\mathbf{3 b}$, although the parent compound $\mathbf{2}$ is almost certainly in the chair form. Changing the solvent from deuteriochloroform to deuteriopyridine only causes an upfield shift of $0.11 \mathrm{ppm}$ in the methyl resonance, whereas had the methyl group been axial, as in $\mathbf{3 b}$, the shift might be expected to be greater than $0.2 \mathrm{ppm}$, so that on this basis $3 \mathbf{a}$ is the preferred conformation [12].

A further consideration is the energy of the 1,3 interaction of the methyl group with the protons of the ring. In a chair form there are two actual interactions whereas in the boat form, the methyl group being equatorial, there are no such interactions and the enthalpy difference is of the order of 6.7 to $7.5 \mathrm{~kJ} / \mathrm{mol}$ [13], which has to be set against the difference in the enthalpy of the boat and chair forms of cyclohexanone, i.e. $11.3 \mathrm{~kJ} / \mathrm{mol}$ [14]. 


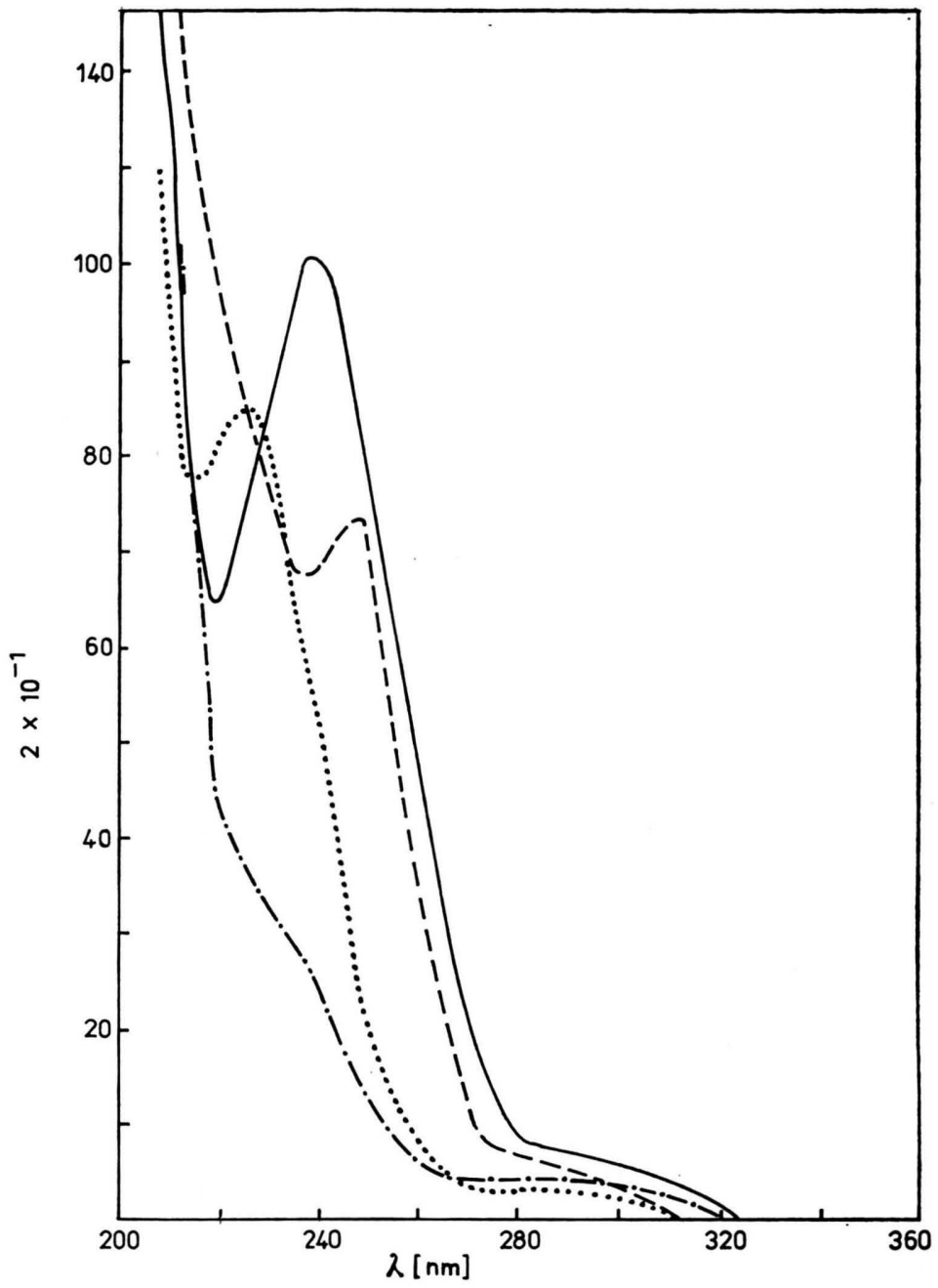

Fig. 2.

UV ketothiane,

-・-・-・* UV hydrosulphide,

....... UV dicarvone sulphide,

- - - - - UV meso dicarvone sulphide.

\section{CD and ORD Spectra}

Figures 1 and 2 show the ORD, CD and UV spectra of the thiane, carvone hydrosulphide and dicarvone sulphide. When the CD spectrum of the thiane is compared with that of the hydrosulphide it is seen that both the 290 and $235 \mathrm{~nm}$ bands have shifted to longer wavelengths, i.e. to 295 and $250 \mathrm{~nm}$ respectively and have changed in sign in the process, whereas a third band just below $220 \mathrm{~nm}$ appears to have the same negative sign in the thiane as in the sulphide. The ORD spectrum of the thiane suggests a positive sign for the bands below $200 \mathrm{~nm}$ whilst that of the hydrosulphide and dicarvone sulphide is probably only indicative of the negative CD absorption at around $210 \mathrm{~nm}$.
The carbonyl $n-\pi^{*}$ transition in the thiane appears negative in the CD at $296 \mathrm{~nm}(\theta=-9340)$, as is a second band at $250 \mathrm{~nm}(\theta=-6560)$, which is probably ascribable to a sulphur transition [11], and that at $c a .205 \mathrm{~nm}$ is also negative (the maximum was not reached). It is, however, interesting to note that, from the general shape of the ORD curve, the absorption below $200 \mathrm{~nm}$ is strongly positive.

One of the interesting features of this series of spectra is that the molar ellipticity of dicarvone sulphide is roughly twice (1.77) that of the carvone hydrosulphide. This means that the actual observed ellipticity for solutions of similar concentration of the sulphide is roughly similar to that of the hydrosulphide. It is also interesting to note that the band 
at about $290 \mathrm{~nm}$ is partially resolved in the hydrosulphide into two peaks, whereas in the dicarvone sulphide only a single peak appears. In the band at $235 \mathrm{~nm}, \theta$ has a value of 85 in the sulphide and 15 in the hydrosulphide; that is, a ratio of between 5 and 6 . This might suggest that there is a conjugation in the dicarvone sulphide, both of the keto group at $290 \mathrm{~nm}$ and of the sulphide group at $235 \mathrm{~nm}$. Conjugation, however, implies co-planarity and at least some bond relationship other than a single bond, but conjugation with the keto group is unlikely to be effective without affecting the stability of the hydrogen on $\mathrm{C} 2$ and, thus, causing the compound to racemise. Another possibility, which seems to be more likely, is that in the dicarvone sulphide there is conformational restriction which gives preference to a conformation with a high activity. It is noteworthy that CD $\lambda_{\max } 290 \mathrm{~nm}$ for the hydrosulphide increases in the dicarvone sulphide by about $5 \mathrm{~nm}$. This bathochromic effect is a good deal smaller than might be expected if the compound were really conjugated. A further possibility is that the two halves of the sulphide molecule lie on top of one another in such a way that there is an interchange between the binding of the keto group and the methylene group in the side chain, which binding could apply to both keto and methylene groups at the same time, thus providing for further restriction of rotation and an interchange of electrons between the methylene and keto groups.

\section{Experimental}

\section{(-)-3-Mercaptodihydrocarvone}

(-)-Carvone ( $28 \mathrm{~g})$ was added dropwise over a period of $1.5 \mathrm{~h}$ to a stirred, saturated solution of hydrogen sulphide in chloroform $(200 \mathrm{ml})$ containing triethylamine $(10 \mathrm{ml})$; hydrogen sulphide gas was passed through the solution for a further $20 \mathrm{~h}$. The temperature of the solution was maintained at $8-10^{\circ} \mathrm{C}$ for the first $5 \mathrm{~h}$ and was then allowed to reach room temperature. The solution was washed with dilute acetic acid $(5 \%, 200 \mathrm{ml})$ and then ten times with water. Evaporation of the solvent after drying $\left(\mathrm{MgSO}_{4}\right)$ left a viscous oil $(30 \mathrm{~g})$ from which (-)-carvone sulphide was precipitated by shaking with petroleum ether $\left(40-60{ }^{\circ} \mathrm{C}\right)$; the oil remaining after evaporation of the petroleum ether was distilled through a $6^{\prime \prime}$ Vigreux column at reduced pressure under nitrogen to yield unreacted (-)carvone $\left(6.7 \mathrm{~g}\right.$, b. p. $\left.65-110^{\circ} \mathrm{C} / 1 \mathrm{~mm}\right)$ and crude (-)-3-mercaptodihydrocarvone (16.8 g, b.p. 148 to $\left.151{ }^{\circ} \mathrm{C} / 0.6 \mathrm{~mm}\right)$. Redistilled, it had b.p. $150-151^{\circ} \mathrm{C} /$ $0.5 \mathrm{~mm}$. Yield $15.8 \mathrm{~g}(46 \%) n_{\mathrm{D}}^{19} 1.5221 ;[\alpha]_{\mathrm{D}}^{20}-6.3^{\circ}$ (c, 4 in chloroform).
$\mathrm{C}_{10} \mathrm{H}_{16} \mathrm{OS}$

Calcd C 65.2 H 8.7 S 17.4,

Found C 65.3 H 8.7 S 17.3.

$v \mathrm{~cm}^{-1} 3100\left(=\mathrm{CH}_{2}\right), 1650(\mathrm{C}=\mathrm{C}), 2575(-\mathrm{SH}), 1710$ (satd. $=\mathrm{C}=0), 890\left(=\mathrm{CH}_{2}\right) ; \delta \mathrm{ppm} .(220 \mathrm{MHz}$, $\left.\mathrm{CDCl}_{3}\right) 1.11\left(\mathrm{~d}, 3 \mathrm{H}, J 6.5 \mathrm{~Hz},-\mathrm{CH}-\mathrm{CH}_{3}\right), 1.22$ $(\mathrm{d}, 1 \mathrm{H}, J 7 \mathrm{~Hz},-\mathrm{SH}), 1.76\left(\mathrm{~s}, 3 \mathrm{H},-\mathrm{CH}_{3}\right), 3.70$ $(\mathrm{m}, J$ 7, 3.8, 3.5, $3.5 \mathrm{~Hz}, \mathrm{H} 3), 4.76$ and 4.81 (s, each $1 \mathrm{H},=\mathrm{CH}_{2}$ ).

\section{(1S, 4S, 5S)-(-)-4,7,7-Trimethyl-6-thiabicyclo- (3,2,1)octan-3-one}

Repetition of the preparation above at room temperature using a small excess of triethylamine (15 ml/25 g of (-)-carvone) gave, in addition to 3-mercaptodihydrocarvone, a small amount of product which, distilled at $124^{\circ} \mathrm{C} / 0.2 \mathrm{~mm}$, slowly solidified. The solid $(0.5 \mathrm{~g})$ recrystallised from aqueous methanol had m. p. $89-90{ }^{\circ} \mathrm{C},[\alpha]_{\mathrm{D}}^{20}-39.5^{\circ}$ (c 2.5 in chloroform, $\mathrm{l}=1$ ).

$\mathrm{C}_{10} \mathrm{H}_{16} \mathrm{OS}$

Calcd C65.2 H8.7 M(mass spec) 184.0922, Found C65.2 H8.8 M(mass spec) 184.0920.

$v \mathrm{~cm}^{-1} 1705$ (satd > $\left.=0\right), 1365,1375\left(-\mathrm{CMe}_{2}\right)$; $\delta$ ppm. $\left(100 \mathrm{MHz}, \mathrm{CDCl}_{3}\right) 1.16(\mathrm{~d}, 3 \mathrm{H}, J 7 \mathrm{~Hz}$, $\left.-\mathrm{CH}-\mathrm{CH}_{3}\right), 1.42\left(\mathrm{~s}, 6 \mathrm{H},-\mathrm{CMe}_{2}\right), 3.42(\mathrm{~m}, 1 \mathrm{H}$, probably $\mathrm{H} 5)$; $\delta$ ppm. $\left(100 \overline{\mathrm{MHz}}, \mathrm{C}_{5} \mathrm{D}_{5} \mathrm{~N}\right), 1.05$ $\left(\mathrm{d}, 3 \mathrm{H}, J 7 \mathrm{~Hz},-\mathrm{CH}-\mathrm{CH}_{3}\right), 1.32$ and 1.36 (s, each $\left.3 \mathrm{H},-\mathrm{CMe}_{2}\right), 3.36(\mathrm{~m}, 1 \overline{\mathrm{H}}$, probably $\mathrm{H} 5)$.

\section{Reaction of (-)-3-mercaptodihydrocarvone with (-)-carvone and (+)-carvone}

(-)-3-Mercaptodihydrocarvone (2.0 g) was added to an ice-cooled, stirred solution of (-)-carvone $(2.0 \mathrm{~g})$ in ethanol $(1 \mathrm{ml})$ saturated with ammonia; the white solid, m.p. $221-222{ }^{\circ} \mathrm{C}$, which precipitated after a few minutes, was identified as (-)-dicarvone sulphide by mixed m.p., $[\alpha]_{\mathrm{D}}^{20}$, and IR spectrum.

When the mercapto-compound $(1.0 \mathrm{~g})$ was allowed to react with $(+)$-carvone $(1 \mathrm{~g})\left(n_{\mathrm{D}}^{13} 1.5018,[\alpha]_{\mathrm{D}}^{20}\right.$ $+58.0^{\circ}$ in chloroform) in ethanol $(0.5 \mathrm{ml})$ as above, a white solid $(0.97 \mathrm{~g})$ was obtained which crystallised from ethyl acetate, had m.p. $197-199^{\circ} \mathrm{C}$.

\section{$\mathrm{C}_{20} \mathrm{H}_{30} \mathrm{O}_{2} \mathrm{~S}$ \\ Calcd C 71.9 H 9.0 S 9.45, \\ Found C 71.6 H 9.0 S 9.5.}

The compound did not show any rotation at the sodium D line. $v \mathrm{~cm}^{-1} 3100\left(=\mathrm{CH}_{2}\right), 1710 \mathrm{sh}, 1705$ $($ satd. $\mathrm{C}=0), 1650(\mathrm{C}=\mathrm{C}), 904,892\left(=\mathrm{CH}_{2}\right), 1710 \mathrm{sh}$, 1705 (satd. $\mathrm{C}=\mathrm{O}), 1650(\mathrm{C}=\mathrm{C}), 904,892\left(=\mathrm{CH}_{2}\right)$.

Thanks are due to the Science Research Council, London, for the 100 and $220 \mathrm{MHz}$ NMR spectra and the mass spectrum, and to the London Borough of Newham for support for LFR. We are grateful to the late Dr. D. L. Marshall for his critical appraisal of this manuscript. 
[1] D. J. Lee, C. J. Timmons, and S. C. Wallwork, J. Chem. Soc. 1962, 3830.

[2] E. E. van Tamelen and E. A. Grant, J. Am. Chem. Soc. 81, 2160 (1959).

[3] A. C. Huitric, J. B. Carr, W. I. Trager, and B. J. Nist, Tetrahedron 19, 2145 (1963).

[4] F. Johnson, N. A. Starkowsky, and W. D. Gurowitz, J. Am. Chem. Soc. 87, 3496 (1965).

[5] A. J. Birch, Ann. Rep. Chem. Soc. 47, 192 (1950).

[6] M. L. Josien, P. Dizabo, and P. Saumagne, Bull. Soc. Chim. Fr. 5 E, 423 (1957).

[7] L. J. Bellamy, Advances in Infrared Group Frequencies, p. 24, Methuen, London 1968. Idem "Infrared Spectra of Complex Molecules", p. 34, Methuen, London 1958.

[8] N. B. Colthup, L. H. Daly, and S. E. Wiberley,
Infrared and Raman Spectra, p. 233, 2nd edition, Academic Press, New York 1975.

[9] Idem, ibid., p. 225.

[10] E. A. Fehnel and M. Carmack, J. Am. Chem. Soc. 71, 84 (1949).

[11] H. H. Jaffé and M. O. Orchin, Theory and Application of Ultraviolet Spectroscopy, pp. 279, 479, Wiley, New York 1962.

[12] J. Ronayne and D. H. Williams in E. F. Mooney (ed.), Ann. Rev. of NMR Spectroscopy, vol. 2, Academic Press, London 1969.

[13] E. L. Eliel, N. L. Allinger, S. J. Angyal, and G. D. Morrison, Conformational analysis, p. 43, Interscience, New York 1965.

[14] N. L. Allinger, J. Am. Chem. Soc. 81, 5727 (1959). 